\title{
Alfabetize: um aplicativo móvel de apoio à alfabetização
}

\author{
Maria Eduarda Q. Barbosa ${ }^{1}$, Naijda Souza ${ }^{2}$, Adilza Silva², Robson Lins ${ }^{1}$ \\ ${ }^{1}$ Centro de Ciências e Tecnologia - Universidade Católica de Pernambuco (UNICAP) \\ Rua do Príncipe,526 - Boa Vista - Recife - PE - Brasil \\ ${ }^{2}$ Centro de Tecnologia, Educação e Cidadania (CETEC) - Avenida Oliveira Lima, 824 \\ Soledade - Recife, PE - Brasil \\ meduarda.qb@gmail.com, naidjal@hotmail.com, adilzagomes@gmail.com, \\ rclec3.unicap.br
}

\begin{abstract}
Resumo. Este trabalho propõe um aplicativo para dispositivos móveis a fim de auxiliar os professores no processo de aprendizagem da língua escrita. $O$ aplicativo, desenvolvido para a plataforma Android, está voltado para crianças que se encontram no nivvel pré-silábico da alfabetização e contempla atividades especialmente desenvolvidas para auxiliar os alunos na transição do nível pré-silábico para o nível silábico. O aplicativo foi desenvolvido com o apoio de duas professoras de pedagogia da Prefeitura da Cidade do Recife e para sua validação aplicou-se um questionário a um conjunto de professores da prefeitura do Recife, que trabalham com tecnologia, após utilizarem a aplicação.
\end{abstract}

\section{Cenário de uso do aplicativo}

A utilização de tecnologias vem se tornando cada vez mais frequente na vida cotidiana das pessoas, seja ela no ramo da saúde, segurança, esportes e como não poderia ser diferente a área educacional vem ganhando mais adeptos. Acredita-se que o uso da tecnologia nas escolas pode agregar valor a qualidade de aprendizagem dos alunos, pois esta ajuda a manter os estudantes mais interessados pelo conteúdo pelo fato da tecnologia proporcionar uma abordagem mais interativa ao aluno.

O processo de alfabetização dos alunos, para muitos educadores, significa associar exercícios repetitivos de codificação e decodificação da língua escrita. Essa metodologia vem sendo questionada visto que o aprendizado da língua é muito mais que simplesmente adquirir códigos. De fato, existem significados e associações de histórias vivenciadas pelo alfabetizando que podem ser utilizadas em sala de aula durante seu processo de alfabetização (Russo, 2012).

Segundo Ferreiro e Teberosky (1986) o processo de aprendizagem da língua não depende apenas do código ou do aluno, mas sim, da interação entre eles. Além disso, o alfabetizando passa por um processo evolutivo durante o aprendizado da língua escrita, a saber:

- Garatujas: nível em que o alfabetizando tem o primeiro contato com o lápis e vai desenvolvendo seus primeiros rabiscos, também conhecidos como garatujas, que inicialmente são desenhos sem figuração e mais tarde se tornam desenhos com figuração. 
VI Congresso Brasileiro de Informática na Educação (CBIE 2017)

Anais dos Workshops do VI Congresso Brasileiro de Informática na Educação (WCBIE 2017)

- Pré-silábico: nível em que a criança já conhece algumas letras e números, porém, estes são apenas símbolos que ainda não fazem sentido para o alfabetizando.

- Silábico: nesse nível, a criança não tem o conhecimento de todas as letras do alfabeto. Logo, eventualmente poderão surgir alguns erros de grafia durante a escrita de algumas palavras.

- Silábico-Alfabético: esse nível tem como hipótese central duas formas de correspondência entre a grafia e o som. A primeira delas é a silábica, no qual o som é produzido por uma única emissão de voz. Já a segunda forma é a alfabética, que consiste em um processo de análise fonético e análise dos fonemas.

- Alfabético: ao chegar nesse nível, antes de ser considerada alfabetizada, a criança compreende que cada um dos caracteres da escrita corresponde a valores menores que a sílaba, conhece o valor sonoro de todas ou quase todas as letras, começa a perceber a lógica utilizada na construção do código da escrita e inicia a construção de escritas alfabéticas.

Nesse contexto evolutivo de aprendizagem da língua escrita, este artigo propõe um aplicativo, intitulado Alfabetize, para dispositivos móveis a fim de auxiliar o alfabetizando na transição do nível pré-silábico para o nível silábico. O aplicativo, desenvolvido para a plataforma Android, destaca-se pela flexibilidade no cadastro de palavras a serem trabalhadas nos exercícios, visto que permite ao professor incluir em tempo real uma palavra diferente das previamente cadastradas. Esta funcionalidade proporciona uma maior dinâmica durante a aula, bem como o uso criativo de novas atividades.

\section{Desenvolvimento do aplicativo alfabetize}

O aplicativo alfabetize, que foi desenvolvido com o acompanhamento de pedagogas, passou por várias etapas até chegar a sua primeira versão. Essas etapas consistem em: estudo pedagógico, revisão de literatura, concepção da interface (telas) e implantação de atividades (exercícios).

Após a definição do objetivo da aplicação foram realizados estudos pedagógicos com a finalidade de entender o processo de alfabetização dos alunos para que o aplicativo pudesse contribuir de maneira eficiente com sua proposta. Esta aplicação tem como embasamento pedagógico a "Psicogênese da língua escrita", proposta por Ferreiro e Teberosky (1986). Neste momento foram definidas as atividades específicas para a hipótese pré-silábica que o projeto irá proporcionar aos professores e alunos. Tais atividades tiveram a colaboração de duas professoras de pedagogia.

Em seguida o aplicativo alfabetize passou por um processo de análise e escolha das tecnologias a serem utilizadas. Consideraram-se dois fatores: o primeiro deles é que o alfabetize deveria ser uma aplicação para dispositivos móveis, pois atualmente os celulares são um dos aparelhos mais utilizados pela população mundial, além de serem dispositivos de fácil acesso; o segundo fator foi a escolha do sistema operacional Android, pois é um dos sistemas operacionais mais utilizados atualmente nos dispositivos móveis e os aparelhos em geral que utilizam este sistema operacional têm um menor custo de aquisição se comparado com os dispositivos baseados no sistema operacional iOS. 
VI Congresso Brasileiro de Informática na Educação (CBIE 2017)

Anais dos Workshops do VI Congresso Brasileiro de Informática na Educação (WCBIE 2017)

Após definir que o front-end do software seria uma aplicação móvel para o sistema Android concebeu-se como seria o back-end do projeto, isto é, o módulo responsável por processar e armazenar os dados gerados pela aplicação. Para o alfabetize escolheuse o Firebase pela redução do tempo de desenvolvimento e pelas funcionalidades que a plataforma da Google oferece (Firebase, 2017).

Depois de passar pelo processo de quais tecnologias utilizar, para tornar possível a proposta do alfabetize, foram realizadas várias pesquisas na Google Play por aplicativos com ênfase no processo de alfabetização de crianças. Essa pesquisa permitiu identificar funcionalidades indesejadas como, por exemplo, muitas informações nas telas.

Com relação ao ambiente de desenvolvimento do alfabetize utilizou-se o Android Studio, que é a IDE oficial de desenvolvimento para o sistema operacional Android, bem como o Firebase que cuida de toda regra de negócio da aplicação. Também foram utilizadas a ferramenta de controle de versão Git6 e o Bitbucket7 para hospedar o projeto.

Para validar este projeto, o aplicativo foi inicialmente apresentado a um grupo de professores da Prefeitura da Cidade do Recife que trabalham com turmas de alfabetização. Em seguida, aplicou-se um questionário com três perguntas. As respostas desse questionário seguidas de comentários de dois professores desse grupo são apresentadas nas Tabelas 1, 2 e 3.

Tabela 1: Primeira pergunta do questionário.

\begin{tabular}{|c|l|}
\hline & $\begin{array}{l}\text { Você considera que o app alfabetize auxilia no processo de } \\
\text { aprendizagem do estudante? }\end{array}$ \\
\hline $\begin{array}{c}\text { Professor } \\
1\end{array}$ & $\begin{array}{l}\text { (x) Sim ( ) Não ( ) Parcialmente. } \\
\text { Comentários: O app consiste em uma ferramenta pedagógica de apoio ao } \\
\text { trabalho desenvolvido pelos educadores, principalmente por permitir uma } \\
\text { atualização coletiva e em tempo real. }\end{array}$ \\
\hline $\begin{array}{c}\text { Professor } \\
2\end{array}$ & $\begin{array}{l}\text { (x) Sim ( ) Não ( ) Parcialmente. } \\
\text { Comentários: Positivo por trabalhar palavras/imagens, palavra como todo } \\
\text { e a análise da escrita da palavra. }\end{array}$ \\
\hline
\end{tabular}

Tabela 2: Segunda pergunta do questionário.

\begin{tabular}{|c|l|}
\hline & O que você achou da interface da aplicação? \\
\hline $\begin{array}{c}\text { Professor } \\
1\end{array}$ & $\begin{array}{l}\text { Consideravelmente bom, será um instrumento de grande utilização. Pois, } \\
\text { não contém muitas informações na tela. Sistema simples de manuseio. }\end{array}$ \\
\hline $\begin{array}{c}\text { Professor } \\
2\end{array}$ & $\begin{array}{l}\text { A interface adotada no aplicativo está bastante "clean" facilitando a } \\
\text { utilização do usuário público alvo, que requer um layout que seja } \\
\text { convidativo e ao mesmo tempo não dispersante da atenção do aluno }\end{array}$ \\
\hline
\end{tabular}


Tabela 3: Terceira pergunta do questionário.

\begin{tabular}{|c|l|}
\hline & $\begin{array}{l}\text { Comparando o app alfabetize aos aplicativos da mesma categoria, } \\
\text { você o considera: }\end{array}$ \\
\hline $\begin{array}{c}\text { Professor } \\
1\end{array}$ & $\begin{array}{l}\text { ( ) Muito semelhante (x) superior ( ) inferior } \\
\text { Comentários: Por conter a edição e o compartilhamento de palavras, } \\
\text { diferente dos outros. }\end{array}$ \\
\hline $\begin{array}{c}\text { Professor } \\
2\end{array}$ & $\begin{array}{l}\text { ( ) Muito semelhante (x) superior ( ) inferior } \\
\text { Comentários: Pois permite o professor trabalhar o banco de palavras do } \\
\text { seu interesse, conforme contexto temático que esteja abordando frente ao } \\
\text { grupo de estudantes. }\end{array}$ \\
\hline
\end{tabular}

\section{Apresentação do aplicativo alfabetize}

O Alfabetize é um aplicativo desenvolvido para a plataforma Android que tem como objetivo auxiliar professores em sala de aula durante a alfabetização de alunos que se encontram na hipótese pré-silábica e estão em processo de avanço para a hipótese silábica.

Apesar de existirem aplicativos que apresentam o mesmo objetivo de atuação, isto é, auxílio na alfabetização de crianças, nas principais lojas de aplicativos como Google Play e App Store, o alfabetize tem como diferencial proporcionar ao professor a possibilidade de adicionar, facilmente, palavras em tempo real, que serão utilizadas nos exercícios disponíveis na aplicação. Outra característica do alfabetize é que essas palavras são compartilhadas entre os usuários da aplicação, ou seja, se um professor acionar a palavra "casa" automaticamente todos terão acesso a mesma nas atividades propostas, sem a necessidade que outro professor cadastre essa mesma palavra posteriormente.

Além disso, o aplicativo disponibiliza quatro tipos de exercícios para trabalhar as seguintes atividades: sílabas, atividade para trabalhar as letras, atividade para a criança trabalhar os sons das letras e uma atividade para a criança associar palavras a imagens, previamente cadastradas pelos professores.

\subsection{Principais telas do aplicativo alfabetize}

Para utilizar o aplicativo o usuário precisará acessar os conteúdos da aplicação através de sua conta já existente como mostra a Figura 1. Caso o usuário não tenha uma conta no aplicativo, o mesmo deverá efetuar o cadastro (ver Figura 2) escolhendo o tipo de usuário: se for professor, terá acesso total as funcionalidades de controle das palavras que são utilizadas nas atividades; se for um usuário do tipo aluno, este só terá acesso as atividades cadastradas no sistema.

Ao efetuar login o usuário será redirecionado para a tela do menu principal, como ilustra a Figura 3. Como pode-se observar, é nesta tela que estão contidas as atividades que poderão ser trabalhadas em sala de aula. Ao acessar o botão "Sons e letras", o usuário será redirecionado para o exercício no qual o usuário irá pressionar um botão para que este escute a letra falada e marque a alternativa correta, como mostra a Figura 4. 
VI Congresso Brasileiro de Informática na Educação (CBIE 2017)

Anais dos Workshops do VI Congresso Brasileiro de Informática na Educação (WCBIE 2017)

Ainda sobre as atividades disponíveis, ao pressionar o botão de imagens e palavras o usuário será redirecionado para a tela deste exercício, no qual o aplicativo irá exibir uma imagem e terá três opções para marcar a palavra correta relacionada a imagem, como mostra a Figura 5.

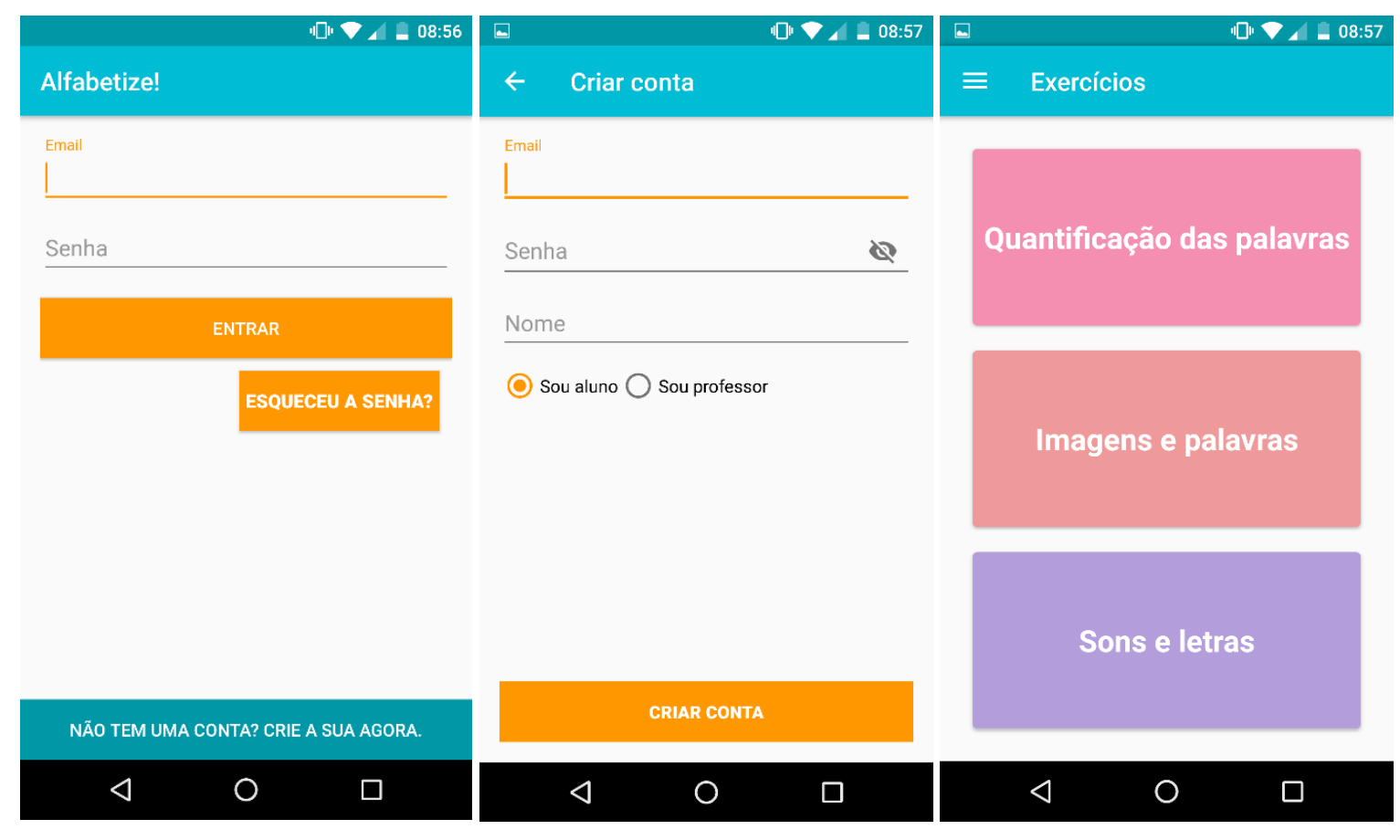

Figura 1: Tela de Login. $\quad$ Figura 2: Tela de criação de conta.

Figura 3: Menu das atividades.

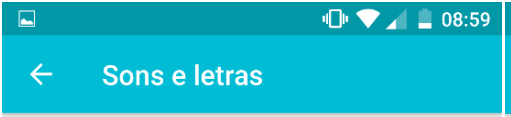

Aperte o botão abaixo, escute 0 som e marque a letra correta

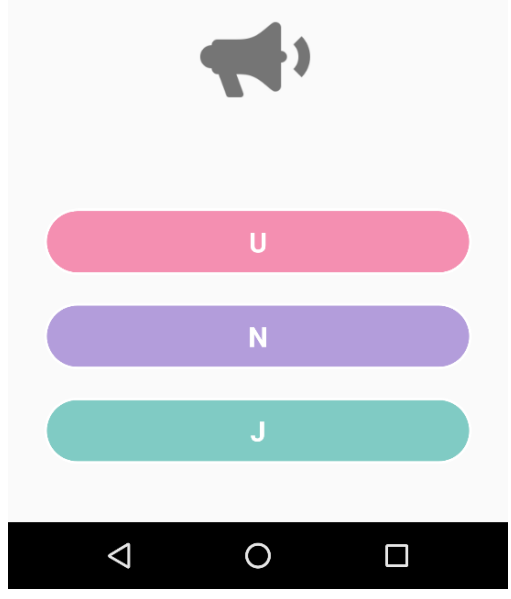

Figura 4: Tela de sons e letras.

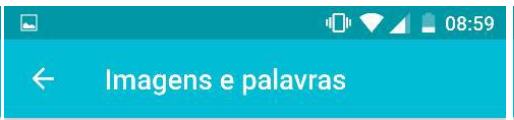

Observe a figura e marque a alternativa correta
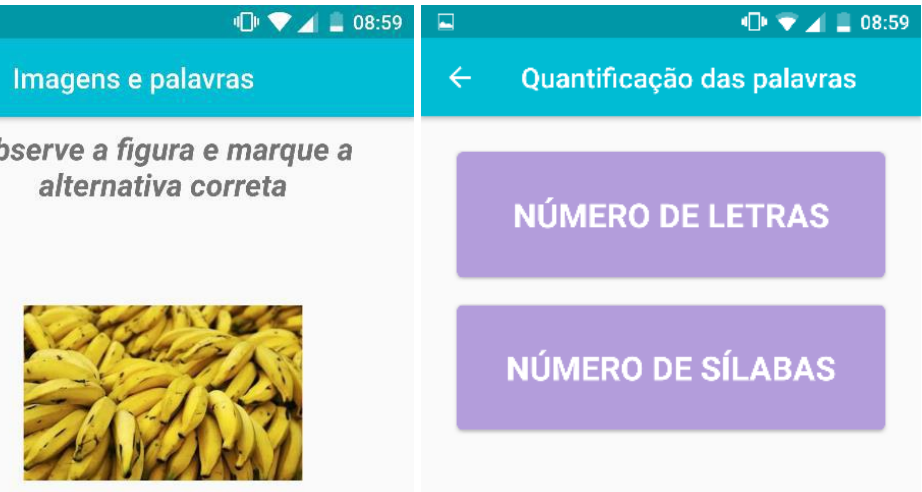

NÚMERO DE LETRAS

NÚMERO DE SÍLABAS

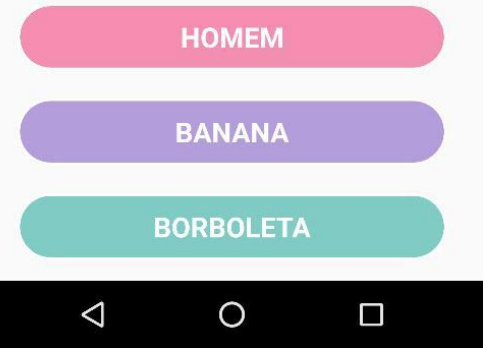

Figura 5: Tela de imagens e palavras.

\section{$\triangleleft$ \\ O \\ $\square$}

Figura 6: Atividade de quantificação. 
VI Congresso Brasileiro de Informática na Educação (CBIE 2017)

Anais dos Workshops do VI Congresso Brasileiro de Informática na Educação (WCBIE 2017)

A Figura 6 ilustra o exercício de quantificação de palavras, que é dividido em dois níveis. O primeiro deles é a quantificação de letras (Figura 7) e o segundo é a quantificação de sílabas (Figura 8).

Para mais informações sobre as telas e fluxo de navegação, acessar o link com um vídeo demonstrativo do uso da aplicação: https://youtube/r0ZqE7fmGzo.

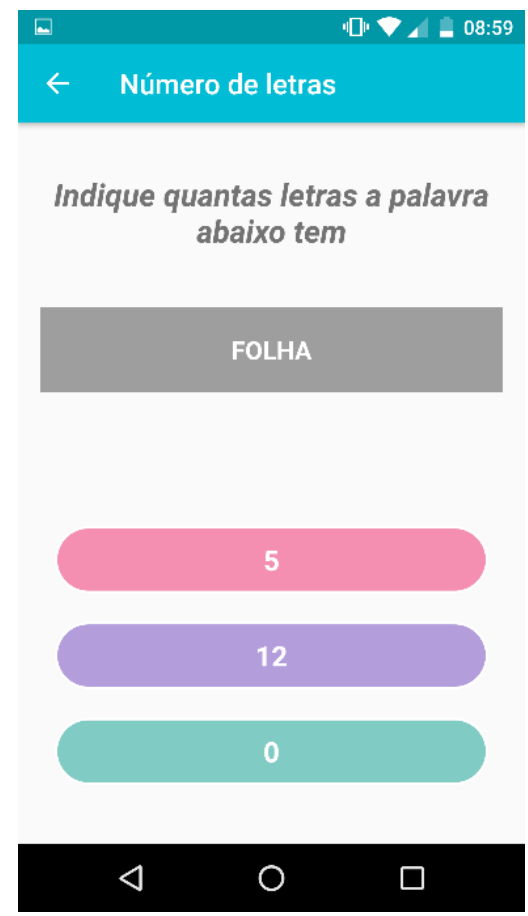

Figura 7: Screenshot do exercício de quantificação de letras.

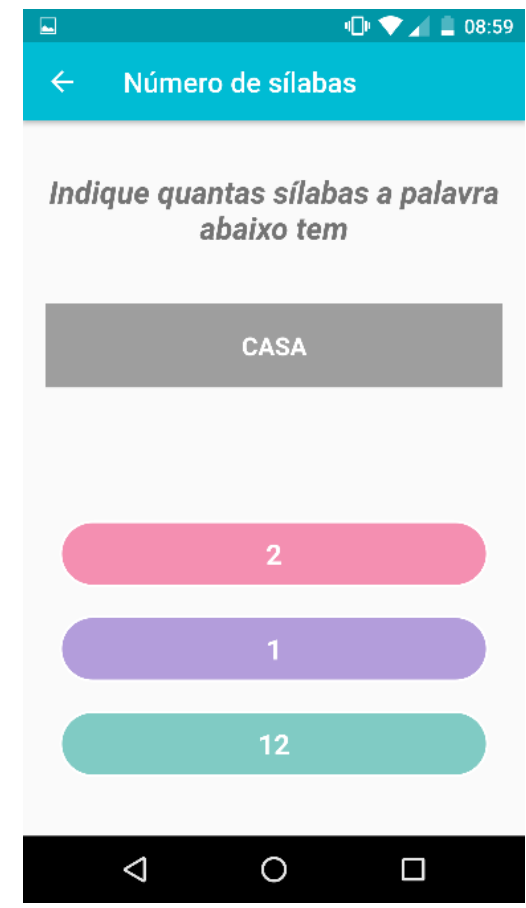

Figura 8: Screenshot do exercício de quantificação de sílabas.

\section{Considerações finais}

Este artigo apresentou um aplicativo, intitulado alfabetize, desenvolvido para a plataforma Android cujo objetivo é auxiliar os professores na alfabetização de alunos que se encontram na hipótese pré-silábica e estão em processo de evolução para a hipótese silábica. Apresentou-se o aplicativo para um grupo de professores que, depois de realizar testes de funcionalidades, responderam um questionário de validação. $O$ desempenho da aplicação foi satisfatório como mostram as Tabelas 1,2 e 3 da Seção 2. Isto se deve ao fato da aplicação ter sido desenvolvida juntamente com profissionais de educação que auxiliaram nas questões pedagógicas, bem como nas funcionalidades. Vale ressaltar que o aplicativo permite ao professor inserir, em tempo real, as palavras que são utilizadas nas atividades disponíveis.

A primeira versão de produção do aplicativo o alfabetize irá disponibilizar a opção aos professores de desabilitar e habilitar em tempo real uma palavra para aumentar o controle do conteúdo que será abordado em sala de aula. Além disso, o aplicativo irá realizar a inclusão da opção para o aluno tentar responder novamente as questões que o mesmo respondeu de forma indevida a fim de propor que o aluno perceba que cometeu 
VI Congresso Brasileiro de Informática na Educação (CBIE 2017)

Anais dos Workshops do VI Congresso Brasileiro de Informática na Educação (WCBIE 2017)

algum equívoco e realize a correção de sua proposta contribuindo para uma melhor aprendizagem. Pretende-se, também, acrescentar a opção de acesso dos exercícios em modo offline para atender as escolas que têm problema de conexão com internet, assim podendo acessar o conteúdo da aplicação mesmo quando estiver sem rede.

\section{Referências}

Android, Desenvolvedores. (2017). "Documentação do Android", https://developer.android.com/index.html, Maio.

Ferreiro, E.; Teberosky, A. (1986). "Psicogênese da língua escrita". Tradução de Diana Myriam Lichtenstein et al. Porto Alegre: Artes Médicas.

Firebase (2017). "Documentação do Firebase", https://firebase.google.com/docs/, Maio.

Mortatti, M. R. L. (2000). “Os sentidos da alfabetização”. São Paulo: UNESP.

Mortatti, M. R. L. (2004). "Educação e letramento”. São Paulo: UNESP.

Russo, M. D. F. (2012). "Alfabetização: um processo em construção”. São Paulo: Saraiva, 6 ${ }^{\mathrm{a}} \mathrm{ed}$.

Teberosky, A. (2001). "Psicopedagogia da linguagem escrita". Tradução de Beatriz Cardoso, Petrópolis: Vozes. 9aㅡ ed. 